\title{
Repair versus Replacement: A Questionnaire Examining the Repair Preferences of Turkish Dentists in Dental Restorations
}

\author{
Ömer Hatipoğlü and Banu Arıcıoğlu ${ }^{2}$ \\ ${ }^{1}$ Department of Restorative Dentistry, Sutcu Imam University, Turkey \\ ${ }^{2}$ Department of Endodontics, Recep Tayyip Erdogan University, Turkey
}

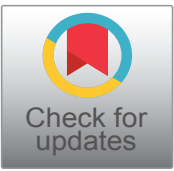

*Corresponding author: Ömer Hatipoğlu, Department of Restorative Dentistry, Sutcu Imam University, Kahramanmaras, Turkey, Tel: +903443003888

\begin{abstract}
To investigate the preferences of Turkish dentists in repairing dental materials. 344 Turkish dentists participated the survey. The questionnaire consisted of 3 sections. In the first part demographic features were asked. The case was presented in the second part; How treatment plans change was asked in the cases such as partial loss of restoration, discoloration, loss of hard substance, secondary caries, marginal discoloration, and marginal gap. In the third part, the most frequently used materials in repairing were demanded. Descriptive statics with Pearson's $x 2$ test was conducted and the risk assessments of factors affecting the choice of repair decision were computed using logistic regression analysis. In amalgam restorations, the participants preferred replacement rather than repair in all cases $(O R>1)$. The replacement was preferred much more and least in the case of secondary caries $(O R=23.57)$ and the case of partial loss of the restoration $(O R=1.18)$, respectively. In composite resin restorations, the participants preferred repair rather than replacement in the cases of partial loss of the restoration and loss of dental hard substance (OR $<1)$. Repair is not preferred many by Turkish dentists. The superior aspects of repair treatment should be further emphasized in dentistry faculties.
\end{abstract}

\section{Keywords}

Decision analysis, Minimal invasive treatment, Repair restorations

\section{Introduction}

Although the improvements in recent years have increased the durability of dental restorations, $\mathrm{pH}$ changes [1], salivary enzymes [2], thermal changes [3] can weaken the mechanical properties of the restorations and fractures can occur in the restorations. In addition, marginal defects, fractures and abrasions can provide a basis for the formation of secondary caries [4]. Also, there may be discolouration due to cigarette, mouthwashes or beverages on dental restorations [5-7]. In these cases, dentists have to make a decision between repairing or replacing the restoration completely.

Minimal invasive treatment is one of the most important principles in modern dentistry. It is the basis of this principle to give as limited damage to healthy tooth tissues and to remove as less tooth tissue as possible. The protection of the dental tissue will ensure that the restorations last longer [8-10]. The complete replacement of the existing restoration expands the preparation size and increases the risk of complications.

In the literature, there is no study examining the repair preferences of Turkish dentists. The purpose of this study was to investigate the cases which Turkish dentists prefer repair instead of replacement. The nullhypotheses of our study were: 1) Repair decisions of Turkish dentists do not vary according to workplace, experience, or gender; 2) The repair choice of Turkish dentists instead of replacement does not change in different cases.

\section{Materials and Methods}

Ethical approval was given by the ethical committee from Sutcu Imam University in Turkey (2018-387). The Sample size was calculated using Raosoft web survey software (http://www.raosoft.com/samplesize.html).

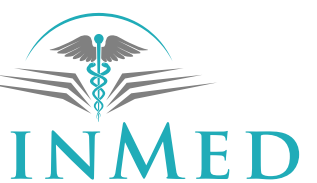

INTERNATIONAL LIBRARY

Citation: Hatipoğlu O, Arıcıoğlu B (2019) Repair versus Replacement: A Questionnaire Examining the Repair Preferences of Turkish Dentists in Dental Restorations. Int J Oral Dent Health 5:077. doi. org/10.23937/2469-5734/1510077

Accepted: January 10, 2019: Published: January 12, 2019

Copyright: (C) 2019 Hatipoğlu O, et al. This is an open-access article distributed under the terms of the Creative Commons Attribution License, which permits unrestricted use, distribution, and reproduction in any medium, provided the original author and source are credited. 


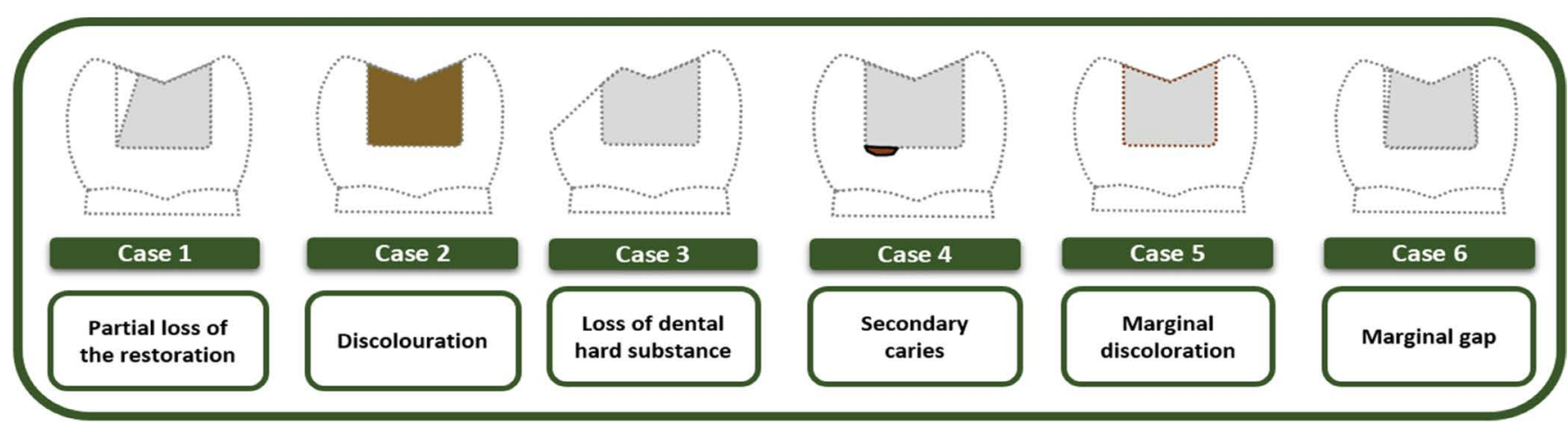

Figure 1: Schematic presentation of six different repair cases.

Table 1: Distribution of Turkish dentists $(n=344)$ according to gender, experience and workplace.

\begin{tabular}{|l|l|l|l|}
\hline Demographic features & Factors & $\mathbf{n}$ & $\%$ \\
\hline \multirow{2}{*}{ Gender } & Male & 154 & 44.8 \\
\hline \multirow{2}{*}{ Experience } & Female & 190 & 55.2 \\
\hline \multirow{3}{*}{ Workplace } & $\leq 10$ Years & 268 & 77.9 \\
\hline & $>10$ Years & 76 & 22.1 \\
\hline & Private & 176 & 51.2 \\
\hline & Public & 70 & 20.3 \\
\cline { 2 - 4 } & Universities & 98 & 28.5 \\
\hline
\end{tabular}

With an $80 \%$ confidence interval, 5\% alpha error, 26674 population size (number of dentists according to TUIK statistical data in Turkey), 268 participants were required [11]. The survey was conducted during October 2018 and the number of participants was 344 dentists. Distribution of Turkish Dentists ( $n=344$ ) according to gender (Male, Female), experience ( $\leq 10$ years $O R>10$ years) and workplace (Public OR University OR Private) was demonstrated in Table 1.

The survey consisted of three sections. In the first section, demographic characteristics were asked to dentists. In the second section, what would your treatment plan for the patient (repair or replacement), if there is partial loss of the restoration (case 1 ), if there is discoloration (case 2), if there is loss of hard substance (case 3 ), if there is secondary caries (case 4), if there is marginal discoloration (case 5), if there is marginal gap (case 6) (Figure 1). The questions were asked separately for resin-based composites (RBCs) and amalgam restorations in each case (Only case 2 was not asked for amalgam restoration). In the third section dental materials they preferred in the repairing was asked to dentists. The repair restoration material preferred for $\mathrm{RBC}$ and amalgam was asked additionally.

Data analysis was performed using the Statistical Package for the Social Sciences version 23.0 (SPSS Inc., Chicago, II., USA). Descriptive statics with Pearson's $\chi^{2}$ test was conducted for associations between the demographic characteristics of the dentists and their repair decisions. Additionally, the risk estimates of factors affecting the choice of repair decision were computed using logistic regression analysis and the effect sizes were computed. The odds ratio (OR) was preferred to calculate the measuring effect size. The probability level for statistical significance was set at $p$ $=0.05$.

\section{Results}

A total of 344 dentists participated in the study; $55.2 \%$ of contributors were female. The ratio of those who have $\leq 10$ years of experience in the study was $77.9 \%$. While the ratio of private clinic dentists who partake in the study was the most $(51.2 \%)$, the ratio of the dentists working at the universities was the least (28.5\%) (Table 1).

In amalgam restorations, the participants preferred replacement rather than repair in all cases (OR $>1$ ). The replacement was preferred much more and least in case $4(O R=23.57)$ and case $1(O R=1.18)$, respectively. In the cases 1,3 and 6 , the females preferred more repair than the males $(p<0.05)$, but in the other cases, there were not any significant differences between genders $(p>0.05)$. In the cases 3 and 4 , there were not any significant differences among workplaces ( $p>$ $0.05)$. But in the case 1 and 6 , participants from public and universities preferred more repair, respectively ( $p$ $<0.05)$. In the case 5 , participants from private clinics preferred less repair $(p<0.05)$. In the case 6 , those who experienced less than 10 years preferred more repair ( $p$ $<0.05$ ), but in the other cases, experience did not affect the decision-making ( $p>0.05)$ (Figure 2).

In $\mathrm{RBC}$ restorations, while the participants preferred repair rather than replacement in the cases 1 and 3 $(O R<1)$, in the other cases they preferred replacement much more $(O R>1)$. In the case 4 , replacement was preferred much more $(O R=23.57)$, but in the case 1 , it was not preferred at all $(O R=0.4)$. In the case 5 , males preferred repair rather than replacement ( $<0.05)$, but in the other cases there were not any significant differences between genders ( $p>0.05$ ). In the case 6 , the participants from the universities preferred repair much more $(p<0.01)$, but in the other cases, there were not any significant differences among the workplaces ( $p$ $>0.05$ ). Experience did not affect the repair decision ( $p$ $>0.05$ ) (Figure 2).

While the most preferred materials in repair were 


\begin{tabular}{|c|c|c|c|c|c|c|c|c|c|c|c|c|}
\hline \multicolumn{7}{|c|}{ REPAIR * REPLACEMENT (Reference: Repair) } & \multirow{2}{*}{\multicolumn{3}{|c|}{$0.25 \quad 0.50$}} & $2.00 \quad 4.00$ & \multirow{2}{*}{$8.00 \quad 16.00$} & \multirow{2}{*}{$32.00 \quad 64.00$} \\
\hline & Cases & \multicolumn{2}{|r|}{ Odds Ratio } & CI Lower limit & CI Upper limit & Weight & & & & & & \\
\hline 1 & Case 1 & \multicolumn{2}{|r|}{1.18} & 0.88 & 1.58 & $20.39 \%$ & 1 & & - & & & \\
\hline 2 & Case 3 & \multicolumn{2}{|r|}{1.73} & 1.28 & 2.34 & $20.37 \%$ & 2 & & & - & & \\
\hline 3 & Case 4 & \multicolumn{2}{|r|}{23.57} & 12.54 & 44.31 & $18.81 \%$ & 3 & & & & . & - \\
\hline 4 & Case 5 & \multicolumn{2}{|r|}{3.20} & 2.30 & 4.44 & $20.27 \%$ & 4 & & & - & & \\
\hline 5 & Case 6 & \multicolumn{2}{|r|}{4.73} & 3.30 & 6.78 & $20.16 \%$ & 5 & & & & & \\
\hline 6 & Amalgam & \multicolumn{2}{|r|}{3.63} & 0.88 & 15.00 & $56.98 \%$ & 6 & & & 0 & & \\
\hline 7 & Case 1 & \multicolumn{2}{|r|}{0.40} & 0.29 & 0.55 & $16.79 \%$ & - & & & & & \\
\hline 8 & Case 2 & \multicolumn{2}{|r|}{$\begin{array}{l}3.00 \\
0.59\end{array}$} & 2.17 & 4.15 & $16.77 \%$ & 8 & & & - & & \\
\hline 9 & Case 3 & & 0.59 & 0.44 & 0.80 & $16.81 \%$ & 9 & - & & & & \\
\hline 10 & Case 4 & \multicolumn{2}{|r|}{23.57} & 12.54 & 44.31 & $16.09 \%$ & 10 & & & & & \\
\hline 11 & Case 5 & \multicolumn{2}{|r|}{2.58} & 1.88 & 3.55 & $16.78 \%$ & 11 & & & $\bullet$ & & \\
\hline 12 & Case 6 & \multicolumn{2}{|r|}{3.30} & 2.37 & 4.60 & $16.76 \%$ & 12 & & & - & & \\
\hline 13 & Composite & \multicolumn{2}{|r|}{2.25} & 0.49 & 10.20 & $43.02 \%$ & 13 & & & - & & \\
\hline 14 & Combined Effect Size & & 2.95 & 1.74 & 5.00 & $100 \%$ & 14 & & & $\mathrm{O}=$ & 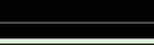 & \\
\hline \multirow[t]{2}{*}{2} & & \multicolumn{3}{|c|}{ GENDER } & \multicolumn{5}{|c|}{ WORKPLACE } & \multicolumn{3}{|c|}{ EXPERIENCE } \\
\hline & Repair \% & Male & Female & P-Value & Private & Public & University & $\mathbf{P - V}$ & & $\leq 10$ Years & $>10$ Years & P-Value \\
\hline \multirow{6}{*}{$\begin{array}{l}\frac{\sum}{d} \\
\frac{d}{\frac{1}{4}} \\
\frac{\sum}{4}\end{array}$} & Case 1 & $39.0 \%$ & $51.6 \%$ & 0.02 & $40.9 \%$ & $62.9 \%$ & $42.9 \%$ & $<0$. & & $47.0 \%$ & $42.1 \%$ & 0.45 \\
\hline & Case 3 & $29.9 \%$ & $42.1 \%$ & 0.02 & $34.1 \%$ & $45.7 \%$ & $34.7 \%$ & 0.2 & & $37.3 \%$ & $34.2 \%$ & 0.62 \\
\hline & Case 4 & $3.9 \%$ & $4.2 \%$ & 0.88 & $4.5 \%$ & $2.9 \%$ & $4.1 \%$ & 0.8 & & $4.5 \%$ & $2.6 \%$ & 0.47 \\
\hline & Case 5 & $22.1 \%$ & $25.3 \%$ & 0.49 & $12.5 \%$ & $37.1 \%$ & $34.7 \%$ & $<0$. & & $25.4 \%$ & $18.4 \%$ & 0.21 \\
\hline & Case 6 & $10.4 \%$ & $23.2 \%$ & $<0.01$ & $11.4 \%$ & $11.4 \%$ & $32.7 \%$ & $<0$. & & $20.1 \%$ & $7.9 \%$ & 0.01 \\
\hline & Case 1 & $67.5 \%$ & $74.7 \%$ & 0.14 & $76.1 \%$ & $65.7 \%$ & $67.3 \%$ & 0.1 & & $73.9 \%$ & $63.2 \%$ & 0.07 \\
\hline \multirow{5}{*}{ 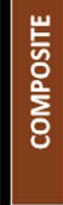 } & Case 2 & $28.6 \%$ & $22.1 \%$ & 0.17 & $25.0 \%$ & $22.9 \%$ & $26.5 \%$ & 0.8 & & $26.9 \%$ & $18.4 \%$ & 0.13 \\
\hline & Case 3 & $58.4 \%$ & $66.3 \%$ & 0.13 & $60.2 \%$ & $62.9 \%$ & $67.3 \%$ & 0.5 & & $61.9 \%$ & $65.8 \%$ & 0.54 \\
\hline & Case 4 & $3.9 \%$ & $4.2 \%$ & 0.88 & $5.7 \%$ & $2.9 \%$ & $2.0 \%$ & 0.2 & & $3 \%$ & $7.9 \%$ & 0.06 \\
\hline & Case 5 & $35.1 \%$ & $22.1 \%$ & $<0.01$ & $27.3 \%$ & $25.7 \%$ & $30.6 \%$ & 0.7 & & $28.4 \%$ & $26.3 \%$ & 0.73 \\
\hline & Case 6 & $20.8 \%$ & $25.3 \%$ & 0.33 & $19.3 \%$ & $17.1 \%$ & $34.7 \%$ & $<0$. & & $25.4 \%$ & $15.8 \%$ & 0.08 \\
\hline
\end{tabular}

Figure 2: The odds ratios of factors affecting the choice of repair decision using logistic regression analysis (1). Distribution (\%) of the preferred repair option according to demographic characteristics for each case (2).



Figure 3: Frequencies of using dental materials in repairing.

diamond finishing instruments (84\%), adhesive systems $(83.1 \%)$, and flow composite $(82 \%)$, the least preferred ones were air abrasion (5\%), silane coupling agent (10.5\%), hydrofluoric acid (14.5\%). A great majority of participants preferred the RBCs in the repair of $\mathrm{RBC}$ restorations (98.8\%) and amalgam restorations (75\%) (Figure 3).

\section{Discussion}

Minimal invasive treatment is the principle to treat the tooth diseases with minimal damage. The repair which was a part of this principle increases its popularity due to its advantages such as maintaining healthy tooth tissue, decreasing the time spent in the clinic, being tolerated more by the patients, causing low economic cost and prolonging the life of the restoration [12]. But according to the type of the cases, the treatment decision of dentists may vary. The development of the education system and the new dental products introduced to the market with the developing technology provide the basis for changes in the past and current treatment approaches.

In our study, Turkish dentists preferred replacement more than repair in all cases generally (Except the cases of partial loss from material and loss of hard substance). 
Likewise, dentists of Saudi Arabia and Pakistan tended to replacement much more $[13,14]$. However, in Germany, Greece, Nigeria, USA, and Norway the repair was more preferred in the majority of treatments [15-19]. This difference may be related to the education curriculum and education system which were improved year by year. In studies conducted on German dentistry students at 3 different times $(2000,2009,2018)$, it is seen that the importance given to repair in education has increased significantly in recent years [20]. However, in our study, younger dentists preferred repairing relatively more, but this difference was not significant in most cases.

The repair was more preferred in RBCs than amalgams in the present study. In the previous studies, it is seen that more replacement was preferred in amalgam restorations $[19,21]$. Especially this difference is more obvious in material and tooth tissue loss. The probable cause of this difference is that amalgam restorations cannot retain a dental material and tooth surface chemically, but RBCs can be bond each other [22]. In addition, the reason which increased the decision may be that amalgam has not sufficient aesthetic quality compatible with tooth colour [23].

In the case of secondary caries in both RBC and amalgam restorations, the replacement was preferred 23 times more than repair by Turkish dentists. These results were consistent with the surveys conducted in USA, England, and Saudi Arabia [14,24]. In contrary, in the studies conducted in Sweden and Germany, more repair was preferred $[20,21]$. In addition, the concern of incomplete removing of caries adequately may be an important factor in the decision to replace restorations completely [19]. At this point, how the question is asked or how the case is introduced are also important. Because the severity and location of secondary caries may change the response [25]. In this study, secondary caries was illustrated under the restoration, it may have increased the preference of replacement instead of repair.

Turkish dentists preferred replacement in the fracture cases and these results are parallel with previous studies $[14,19,21,24,26]$. Fracture is one of the most common complications after dental treatments. In many studies, it has been reported that one of the most important factors in choosing repair treatment is to maintain a healthy tooth tissue $[14,16,26]$. However, the complete renewal of the restoration may cause that occur more tissue loss in the already broken tooth. Especially in these cases, the other reasons why dentists prefer more repair may be those repair treatment saves time and reduces cost [27]. In the present study, the fact that dentists working in the public health prefer more repairs in cases of broken amalgam supports this proposition. In a previous study, we concluded that dentists working in public healths prefer treatments that take less time because of their intense workload [28].

Especially in amalgam cases, it is seen that females prefer more repair than males. Likewise, in our previous study, we found that female dentists are more prone to minimal invasive treatment [28]. But in other countries, the gender factor did not affect the decision of repair $[18,19,21]$. Obviously, it is hard to explain this result, but a reason for this difference may be that they did not research on amalgam restoration in their studies. Because, in our study, this difference was observed only in amalgam restorations.

$\mathrm{RBC}$ was the most preferred restoration material in repairing dental restorations. These results are in line with previous studies $[14,19,21,29]$. The decline of the number of amalgam restorations that were used due to aesthetic requirements in recent years, having advantages of RBC restorations such as being more suitable for minimally invasive treatment and being ability chemically bonding to tooth tissue may play the important roles in this result [30]. In many countries, the use of amalgam has decreased considerably compared to the past [31].

Bonding agent application and finishing instruments are routinely used in the repair of restorations. It has been reported in several studies that silanes improve the bond strength at the repair interface [32-34]. However, currently, some of the recent bonding systems contain silanes, which do not require an extra silanization process. Perhaps this is the reason why it is used less in our study. While some studies were consistent with this result [18], some studies found that the application was satisfactory [21]. As for air abrasion, numerous studies have shown that significantly improves bond strength in the repair of RBC restorations [35-37]. However, only $5 \%$ of Turkish dentists responded that they use air abrasion in the treatment of repair.

\section{Conclusion}

The null-hypotheses were rejected; The demographic attributes of Turkish dentists, such as gender, experience, and the workplace, can change the repair decision. The dentists working in the public health can be prone to repair more because of saving time. Furthermore, the repair decision may vary according to each case. While replacement was more preferred in the case of seconder caries, the repair was more preferred in the cases of fracture. The concern of incomplete removing of caries adequately may have affected the decision. The advantages of repair treatment should be emphasized more in dentistry faculties, so that the principle of minimal invasive treatment will become more widespread among Turkish dentists.

\section{Acknowledgements}

No potential acknowledgement relevant to this article was reported. 


\section{Disclosure Statement}

The authors declare that they have no conflict of interest.

\section{Funding}

None.

\section{References}

1. Bagheri R, Tyas MJ, Burrow MF (2007) Subsurface degradation of resin-based composites. Dent Mater 23: 944-951.

2. Jaffer F, Finer Y, Santerre JP (2002) Interactions between resin monomers and commercial composite resins with human saliva derived esterases. Biomaterials 23: 17071719.

3. Mair LH (1989) Surface permeability and degradation of dental composites resulting from oral temperature changes. Dent Mater 5: 247-255.

4. Manhart J, Chen H, Hamm G, Hickel R (2004) Review of the clinical survival of direct and indirect restorations in posterior teeth of the permanent dentition. Oper Dent 29: 481-508.

5. Karadas M (2016) The effect of different beverages on the color and translucency of flowable composites. Scanning 38: 701-709.

6. Karadas M, Hatipoglu O (2015) Efficacy of mouthwashes containing hydrogen peroxide on tooth whitening. TSWJ 2015.

7. Zhao X, Zanetti F, Majeed S, Pan J, Malmstrom H, et al. (2017) Effects of cigarette smoking on color stability of dental resin composites. Am J Dent 30: 316-322.

8. Fernandez E, Martin J, Vildosola P, Oliveira Junior OB, Gordan V, et al. (2015) Can repair increase the longevity of composite resins? Results of a 10 -year clinical trial. J Dent 43: $279-286$.

9. Martin J, Fernandez E, Estay J, Gordan VV, Mjor IA, et al. (2013) Minimal invasive treatment for defective restorations: Five-year results using sealants. Oper Dent 38: 125-133.

10. Opdam NJ, Bronkhorst EM, Loomans BA, Huysmans MC (2012) Longevity of repaired restorations: A practice based study. J Dent 40: 829-835.

\section{TUIK Statistical Data in Turkey}

12. Anusavice KJ (1995) Preservative dentistry: The standard of care for the 21st century. J Public Health Dent 55: 67-68.

13. Fayyaz A, Fareed MA, Ehsan S, Baig QA, Noor NA (2015) Repair or replacement of defective direct composite restorations: A survey of dentists. JPDA 24.

14. Yousef MK, Khoja NH (2009) Repair and replacement perception of dental restorations. JKAU Med Sci 16: 75-85.

15. Maria A, Charikleia P, Panagiotis L (2017) Attitudes of greek dentists towards repair of conservative restorations. An online survey. Int Dent J 67: 351-359.

16. Abiodun OA, Ayamma UU, Olabisi HO (2012) Repair of defective composite resin restoration: Current trend among conservative dentists in Nigeria. Nig Q J Hosp Med 22: 296299

17. Heaven TJ, Gordan VV, Litaker MS, Fellows JL, Rindal DB, et al. (2013) Agreement among dentist's restorative treatment planning thresholds for primary occlusal caries, primary proximal caries, and existing restorations: Findings from the national dental practice-based research network. J Dent 41: 718-725.

18. Staxrud F, Tveit AB, Rukke HV, Kopperud SE (2016) Repair of defective composite restorations. A questionnaire study among dentists in the public dental service in Norway. $\mathrm{J}$ Dent 52: 50-54.

19. Kanzow P, Hoffmann R, Tschammler C, Kruppa J, Rodig T, et al. (2017) Attitudes, practice, and experience of German dentists regarding repair restorations. Clin Oral Investig 21: 1087-1093.

20. Kanzow P, Wiegand A, Wilson NHF, Lynch CD, Blum IR (2018) Contemporary teaching of restoration repair at dental schools in Germany-close to universality and consistency. J Dent 75: 121-124.

21. Kanzow $\mathrm{P}$, Dieckmann $\mathrm{P}$, Hausdorfer $\mathrm{T}$, Attin $\mathrm{T}$, Wiegand A, et al. (2017) Repair restorations: Questionnaire survey among dentists in the Canton of Zurich, Switzerland. Swiss Dent J 127: 300-311.

22. Moraschini V, Fai CK, Alto RM, Dos Santos GO (2015) Amalgam and resin composite longevity of posterior restorations: A systematic review and meta-analysis. J Dent 43: 1043-1050.

23. Gordan VV, Riley III J, Geraldeli S, Williams OD, Spoto III JC, et al. (2014) The decision to repair or replace a defective restoration is affected by who placed the original restoration: Findings from the national dental pbrn. J Dent 42: 1528-1534.

24. Setcos J, Khosravi R, Wilson NH, Shen C, Yang M, et al. (2004) Repair or replacement of amalgam restorations: Decisions at a USA and a UK dental school. Oper Dent 29: 392-397.

25. Alencar de VRCT, Cavalcante M, Firmino R, Santos J, de Lima JPM (2018) Composite resin repair: Systematic review. JDPH 9.

26. Blum IR, Newton JT, Wilson NH (2005) A cohort investigation of the changes in vocational dental practitioner's views on repairing defective direct composite restorations. $\mathrm{Br}$ Dent J 27-30.

27. Blum IR, Lynch CD, Wilson NH (2014) Factors influencing repair of dental restorations with resin composite. Clin Cosmet investing Dent 6: 81-87.

28. Hatipoglu $O$ and Temur KT (2018) The approaches of Turkish dentists to the invasive treatment. Int Dent Res 8: 56-62.

29. Kopperud SE, Staxrud F, Espelid I, Tveit AB (2016) The post-amalgam era: Norwegian dentist's experiences with composite resins and repair of defective amalgam restorations. Int J Environ Res Public Health 13: 441.

30. Sunnegardh-Grönberg K, van Dijken JW, Funegard U, Lindberg A, Nilsson M (2009) Selection of dental materials and longevity of replaced restorations in public dental health clinics in northern Sweden. J Dent 37: 673-678.

31. Opdam NJ, Bronkhorst EM, Roeters JM, Loomans BA (2007) A retrospective clinical study on longevity of posterior composite and amalgam restorations. Dental Mater 23: 2-8.

32. Staxrud F, Dahl JE (2015) Silanising agents promote resincomposite repair. Int Dent J 65: 311-315.

33. Lung CY, Matinlinna JP (2012) Aspects of silane coupling agents and surface conditioning in dentistry: An overview. Dent Mater 28: 467-477. 
34. Eliasson S, Tibballs J, Dahl JE (2014) Effect of different surface treatments and adhesives on repair bond strength of resin composites after one and 12 months of storage using an improved microtensile test method. Oper Dent 39: 206-216.

35. Brendeke J, Özcan M (2007) Effect of physicochemical aging conditions on the composite-composite repair bond strength. J Adhes Dent 9: 399-406.
36. Özcan M, Alander P, Vallittu P, Huysmans MC, Kalk W (2005) Effect of three surface conditioning methods to improve bond strength of particulate filler resin composites. J Mater Sci Mater Med 16: 21-27.

37. Souza MO, Leitune VC, Rodrigues SB, Samuel SM, Collares FM (2017) One-year aging effects on microtensile bond strengths of composite and repairs with different surface treatments. Braz Oral Res 31: 4. 